\title{
Las ontologías de lo común en la estética $y$ en el arte actuales*
} Ontologies of the common in Aesthetics and Art today

\author{
JoRDi MASSÓ CASTILlA
}

Universidad Complutense de Madrid

\begin{abstract}
RESUMEN. En las últimas décadas, dos líneas de pensamiento han querido hacerse cargo de la necesidad de pensar "lo común" desde coordenadas ontológicas. Una, representada principalmente por Jean-Luc Nancy y Alain Badiou, retoma los análisis de Heidegger sobre el Mitsein; la otra parte de los análisis que Toni Negri hace de la noción de "multitud" de Spinoza. Estas dos "ontologías de lo común" han dado pie a sendas estéticas que persiguen una finalidad política. Este trabajo estudia estas tendencias con el fin de determinar qué tipo de noción de "lo común" manejan. La tesis esgrimida es la de que la interpretación que hacen de aquellas ontologías es errónea y que la "comunidad" presente en ellas está más próxima al sensus communis kantiano.
\end{abstract}

Palabras clave: Ontología, Estética, Arte, común, comunidad, Heidegger, Spinoza, Kant

\section{Introducción}

Una de las discusiones filosóficas más intensas y de mayor recorrido de las tres últimas décadas es la que tiene por asunto el concepto, devenido en problema, de lo común, junto al de comunidad. Sin duda, el ámbito en el que este debate ha sido más producti-
ABSTRACT. In recent decades, two lines of thought have wanted to take care of the need to think "the common" from ontological coordinates. One, represented mainly by Jean-Luc Nancy and Alain Badiou, takes up heideggerian analysis on Mitsein. The other one starts of Toni Negri's analysis of Spinoza's notion of "multitude". These "ontologies of the common" have given rise led to many Aesthetic tendencies pursuing a political purpose. This paper examines these trends in order to determine what kind of notion of "the common" they are using. The theory put forward is that their interpretation of those ontologies is wrong and that the "community" present in them is closer to the Kantian sensus communis.

Key words: Ontology, Aesthetics, Art, Common, Community, Heidegger, Spinoza, Kant

vo es el político. Desde los años 80 varios autores del ámbito anglosajón recuperaron la figura de la comunidad aristotélica para acuñar un neo-comunitarismo enfrentado tanto al neoliberalismo imperante como a las posiciones neo-kantianas que dominaban los enfoques éticos y políticos del pensamiento contemporáneo. 
Paralelamente a esta discusión, en la que intervenían pensadores como Charles Taylor, Alasdair MacIntyre, Michael Sandel o Michel Waltzer -los llamados "comunitaristas"-, y en la que ocasionalmente se han escuchado voces de autores europeos, como Jürgen Habermas o Roberto Esposito, dos filósofos franceses, Jean-Luc Nancy y Maurice Blanchot, entablaban un diálogo en el que se cuestionaba la posibilidad de configurar una comunidad que no se definiese por la fijación de una identidad compartida por todos sus miembros. Para estos autores, en el mismo instante en el que se delimita un espacio de lo común señalando la presencia de determinados rasgos compartidos, se produce una exclusión de quien no se ajusta a ellos y que es considerado desde ese momento como el extraño, el Otro o, incluso, el enemigo. La solución que ofrecen Blanchot, en La communauté inavouable, y Nancy, en La communauté désoeuvrée ${ }^{l}$, conduce a una paradoja que desafía al pensamiento y que para un buen número de autores no es sino una aporía, cuando no un mero juego lingüístico ${ }^{2}$. Siguiendo a Bataille, Blanchot y Nancy afirman que lo único que pueden compartir los integrantes de una comunidad es, precisamente, la ausencia de una identidad común. Esa fórmula se presenta como la única forma de impedir exclusiones y antagonismos, aun a costa de vaciar de todo contenido identitario a la idea de comunidad $^{3}$.

Lo que la conversación entre Blanchot y Nancy ponía de relieve es que pensar en nuestros tiempos lo común implica meditar acerca de lo que puede unir a los sujetos que se consideran pertenecientes a una comunidad. Como bien apunta Judith Revel, el pensamiento de lo común conlleva necesaria- mente una nueva ontología de la comunidad en la que esa forma de ser, el ser-con-losdemás, ocupa el primer plano ${ }^{4}$. Pocas dudas caben respecto a que el primer autor en esbozar una ontología que propone nuevas formas de intersubjetividad sin remitir a relaciones entre conciencias -siempre dependientes del esquema sujeto-objeto-, fue Heidegger. Su crítica al sujeto de la metafísica, que tiene en el cogito cartesiano a su más ilustre representante y que encuentra en el Espíritu hegeliano su epítome, vino acompañada de la intuición de que ese ente cuyo modo de ser es el Dasein, poseía como uno de sus rasgos existenciales el "estar-con" [Mitsein] los demás:

Los otros no comparecen en una aprehensión de sí mismo que empezaría por distinguir el propio sujeto, inmediatamente presente, de los otros sujetos, también presentes; es decir, no comparecen en una primaria mirada sobre sí mismo, que haría posible establecer en término de comparación de una diferencia. Los otros comparecen desde el mundo en el que el Dasein circunspectivamente ocupado se mueve por su propia esencia. ${ }^{5}$

Por ello, concluye Heidegger que "el estar-en es un coestar con los otros. El ser-ensí intramundano de éstos es la coexistencia [Mitdasein]"6. Con este pensamiento, la metafísica sustancialista, asentada en la contraposición entre un sujeto (Yo, Espíritu, conciencia, psiché, cogito...) y un objeto (No-Yo, mundo, fenómeno...), se vio sometida a un nuevo giro copernicano. La epistemología procedente de aquella ontología y basada en la verdad como adequatio; la estética dependiente del concepto de mimesis y para la que la belleza está en función de la proximidad ontológica respecto a un modelo; 
la ética, conformada a partir de ese diálogo entre un Yo y un Tú, que diría Buber; o la política, entendida como la puesta en marcha de mecanismos de representación, exigían ser replanteadas a partir de los nuevos presupuestos de la analítica existencial heideggeriana, en especial desde el Mitsein.

\section{Hacia una ontología de lo común}

Heidegger, empero, pronto olvidó su hallazgo, que abría las puertas a esa nueva intersubjetividad, el Mitsein, que nada tenía que ver con la de la fenomenología husserliana en la que él se había formado. No hay muchas más huellas de aquel pensamiento en los textos posteriores a Ser y tiempo, como sí las hay, en cambio, de un concepto que entra en confrontación con aquél: el pueblo [Volk]. Como es sabido, hacia el final de su gran obra, Heidegger liga fatalmente el Mitsein, de carácter siempre existencial, con una determinación óntica de su avenir: "pero, si el Dasein destinal existe esencialmente, en cuanto estar-en-el-mundo, coestando con otros, su acontecer es un co-acontecer, y queda determinado como destino común [Geschick]. Con este vocablo designamos el acontecer de la comunidad, del pueblo"7. De esta forma, el modo de ser-con-losdemás asume los rasgos de una figura ${ }^{8}$ determinada, el pueblo, que poco tiempo después se identifica con el alemán. Y por lo que respecta al destino al que estaba abocado, se trataba del que habían maquinado los ideólogos del nazismo.

Mucho se ha debatido -o, más bien, polemizado- respecto a la proximidad de Heidegger al nazismo. No volveré, por ello, a repasar los argumentos exculpatorios o incriminatorios que, en último término, nos ale- jarían de lo que nos interesa en el presente estudio, a saber: la vinculación de lo que denominaré "las nuevas ontologías de lo común" con la estética contemporánea. No obstante, por ser el punto de partida de buena parte de ellas una lectura del Mitsein heideggeriano, es preciso recuperar el momento en el que los filósofos que siguen la estela del alemán se vuelven hacia ese ser-con que debiera haber dado lugar a una "analítica co-existencial" del Dasein. Si no lo propició fue porque Heidegger no quiso o no pudo desarrollar las implicaciones del "con" (Mit-). De ahí arranca la filosofía de Jean-Luc Nancy: «he preferido por tanto acabar concentrando el trabajo en torno al "con": casi indiscernible del "co-" de la comunidad, aquél lleva sin embargo consigo un índice más neto del apartamiento en el corazón de la proximidad y de la intimidad. (En este sentido, es preciso llevar más lejos un análisis del Mitdasein dejado en suspenso en Heidegger ${ }^{10} \gg$. Precisamente, es ese "estar-juntos sin ensamblaje" lo que debe ser pensado, y de un modo tal que evite caer en los errores en los que incurrió Heidegger. Desde principios de los años setenta del pasado siglo venimos asistiendo a una constante acuñación de esas "ontologías de lo común": Antonio Negri, Michael Hardt, Paolo Virno, Maurice Blanchot, Alain Badiou, Jean-Luc Nancy o Giorgio Agamben son algunos de los filósofos que han abordado la cuestión desde conceptos como el de "multitud", "comunidad desobrada/inconfesable" o "lo múltiple". Todos ellos se hacen cargo de la crítica del sujeto de la metafísica, que se presenta como una sustancia idéntica a sí misma, inmanente y con unas propiedades particulares que le confieren su identidad. Pensar la comunidad desde esa premisa exige entonces evitar hacer 
de ella un ente sustancial como lo acabó siendo el Mitsein heideggeriano cuando se identificó con el pueblo alemán. Si vuelvo a subrayar esta palabra, es porque la constitución de un sujeto semejante es siempre un proceso de búsqueda de una identidad; en el caso concreto de Heidegger, una construcción que rastreó sus caracteres entre los mitos fundacionales del imaginario alemán ${ }^{11}$. Lo común hacia donde apuntan estos filósofos no podrá ser nunca un ámbito, un fondo, un sustrato, que permita una identificación, sino, en palabras del propio Nancy, lo que paradójicamente impide que esto suceda. De ahí que lo compartido por los miembros de esta comunidad sea una nada: un carecer de algo en común, salvo el hecho de ser-encomún. Esto es lo que debería haber desarrollado Heidegger hasta sus últimas consecuencias:

El tema del ser-con y de la co-originariedad debe ser renovado y debe "reiniciar" la analítica existencial por cuanto ésta quiere responder a la cuestión del sentido del ser, o del ser en cuanto sentido. Pero si el sentido del ser se indica, para empezar, al poner en juego el ser en el Dasein y como Dasein, entonces, precisamente en cuanto sentido, este poner en juego (este "se trata del ser") no puede confirmarse y exponerse, de entrada, más que desde el modo del ser-con: puesto que por lo que respecta al sentido, nunca hay uno, sino siempre de uno hacia otro, siempre entre uno y el otro. ${ }^{12}$

De esta manera, la lectura que hace Nancy del Mitsein se sitúa en el borde entre lo individual y lo colectivo, entre un plano de inmanencia y otro de trascendencia, a salvo, pretendidamente, de la proximidad o de la confusión con la sustancia metafísica.
La fórmula que expresa el núcleo de esta nueva ontología es la de "ser singular plural", en donde "ser", como insistió Heidegger, actúa como verbo transitivo y no como sustantivo. Tenemos así definida en sus principales rasgos a la primera de las "ontologías de lo común" que buscan pensar este elemento compartido sin considerarlo la raiz de una identidad, y en la que, junto al propio Nancy, encontramos a filósofos como Philippe Lacoue-Labarthe, Roberto Esposito, Giorgio Agamben y Alain Badiou. De estos cuatro autores, nos detendremos en los dos últimos por cuanto su pensamiento ofrece más divergencias respecto al de Nancy, lo que no sucede en el caso de Lacoue-Labarthe y de Esposito, muy apegados a la ontología de aquél. Agamben firma uno de los hitos del pensamiento de lo común actuales, La comunidad que viene, en el que la singularidad adopta la forma del "cualsea", carente de toda propiedad identitaria y reacia a adoptar la forma de una individualidad que perdiera de vista el componente "común". Su comunidad expone esa falta de condición de pertenencia, esa "nada en común" de la que habla Nancy. En realidad, el pensamiento de la comunidad que encontramos en Agamben no difiere mucho del que desarrolla el filósofo francés. Si acaso, los referentes ontológicos están más difuminados en el caso del italiano, a lo que habría que añadir que Agamben plantea con más insistencia que los demás el papel que desempeña el lenguaje en esa comunidad de "singularidades cualsea" en cuanto posibilidad misma de la existencia:

La exposición, o sea, el ser tal cual, no es alguno de los predicados reales (el ser rojo, caliente, pequeño, liso...), pero tampoco es diferente de ellos (de otra manera sería algo otro que se añadiría al 
concepto de una cosa, por tanto, todavía un predicado real. [...] Mientras los predicados reales expresan relaciones en el interior del lenguaje, la exposición es lo que adviene a cualquier cosa (más precisamente: el tener lugar de cualsea cosa) por el hecho de estar en relación con el lenguaje, de ser-dicho. [...] La existencia como exposición es el ser-tal de un cual. $^{13}$

En esa "exposición” resuenan ecos de la $e k$-sistencia heideggeriana, con la que el filósofo alemán quiso subrayar por un lado el carácter "yecto" que tiene el Dasein y, por otro, la apertura existencial constitutiva de ese mismo ente. Lo cual prueba, una vez más, el peso que Heidegger tiene en estas "ontologías de lo común" que intentamos caracterizar. Lo mismo cabe decirse de la última de las construcciones que examinamos y que persigue alcanzar el deseado equilibrio entre lo singular y lo plural. Me refiero al sistema filosófico de Alain Badiou, organizado en torno a su noción del "múltiple sinuno": "la decisión inicial es entonces la de sostener que aquello que es pensable respecto al ser se mantiene en la forma de lo múltiple radical, de lo múltiple que nada tiene que ver con el poder del uno. De lo que he denominado, en L'Être et l'événement, lo múltiple sin-uno"14. La afirmación radical de la multiplicidad no subsumible en totalidad alguna, tal es la tesis de un filósofo que, no obstante, no renuncia a cartografiar o estructurar este universo de lo múltiple por medio de la teoría matemática de los conjuntos. En último término, lo múltiple en Badiou queda sometido a las Ideas matemáticas platónicas, al "matema". La pirueta a la que se somete al pensamiento en la obra de este filósofo es, ciertamente, vertiginosa: nada menos que armonizar a Heidegger con Platón ${ }^{15}$, este último principal culpable para el alemán del "olvido del ser" que impuso la metafísica tradicional.

Así pues, la ontología de Badiou, de la que más adelante examinaremos su consecuencia en el dominio estético, parte también del Mitsein heideggeriano, si bien precisa de un ordenamiento ausente en las otras propuestas ontológicas examinadas. Eso es lo que le conduce al platonismo en busca, no tanto de arquetipos como de esquemas que puedan introducir cierto orden en el ámbito de lo múltiple, que, no obstante, no llega a someterlo al imperio de una totalidad. Hay por ello una recuperación del ser de la metafísica -no en vano su principal obra se titula El ser y el acontecimiento, recuperando así su carácter sustantivo-, aun cuando intente compatibilizarlo con un pensamiento del acontecimiento que, de nuevo, remite al Ereignis de Heidegger. Lo más significativo en su filosofía es que encuentra en Spinoza un precedente de su idea de un múltiple "que no se compone más que de multiplicidades"16:

Compartimos con Deleuze la convicción (a mi modo de ver de carácter político) de que todo pensamiento verdadero es pensamiento de las singularidades. Pero en la medida en que las multiplicidades actuales son siempre para Deleuze modalidades puramente formales, y únicamente lo Virtual dispensa de manera unívoca el sentido, sostendremos que no hay otra forma de pensar más que clasificando las diferentes maneras que tiene una singularidad de no ser ontológicamente singular. Esto es, los diferentes modos de actualización. Es, por lo demás, la cruz del spinozismo, cuya teoría de las "cosas singulares" oscila entre un esquematismo de la causalidad (una cosa es un conjunto de modos que producen un 
efecto único) y un esquematismo de la expresión (una cosa testimonia la infinita potencia de la sustancia). ${ }^{17}$

Spinoza es, junto a Heidegger, la otra referencia de las nuevas ontologías de lo común. Y, así como hemos distinguido una línea completamente marcada por la herencia heideggeriana, no sólo a través de la idea del Mitsein, sino también de otras como la "ek-sistencia", el "ser-en-el-mundo" o el "acontecimiento", podría señalarse otra rama para la que las nociones spinozianas de "potencia", "cuerpo" y, sobre todo, "multitud", son centrales. Los principales representantes de esta segunda vía son Toni Negri y Michael Hardt, además de Paolo Virno, Maurizio Lazzarato y, más recientemente, Judith Revel. Las intenciones políticas o, mejor dicho, de aplicación práctica, que guían a este otro pensamiento sobre el ser son evidentes. La crítica del sujeto sustancial de la metafísica, a cargo, entre otros, de Heidegger, también había afectado a otros conceptos básicos para el pensamiento político clásico, tales como "representación”, "contrato", "pueblo" o "soberanía". Sin ellos, la política debía hacerse -y pensarse- por otros medios distintos. El primer problema que se planteaba era el de señalar sin identificar, esto es, sin recuperar las viejas identidades con las que operaba la política, a los nuevos agentes, nuevas subjetividades alejadas de aquella idea de Sujeto y que en un momento dado había adoptado la forma, como se ha explicado, del pueblo alemán, si no salimos de Heidegger. La "multitud" de Spinoza se antojaba una solución intermedia entre el sujeto de la metafísica, preso de aquellas determinaciones ya deconstruídas (identidad, soberanía, propiedad...), y ese "ser singular plural" que, en cuanto modo de ser, difícilmente podía salir de su torre de marfil ontológica para "mancharse las manos" en política. En Spinoza, aquellos autores encontraron un pensamiento para el que el sujeto era, ante todo, un entramado de relaciones colectivas de potencia que albergaba un pensamiento de la vida como subversión. Por eso, para quien como Negri, habían asistido al derrumbe del comunismo, Spinoza suponía una esperanza por recuperar su esencia: "si en el «regreso a Spinoza» se manifiesta entonces una experiencia ligada a la crisis del marxismo, hay que añadir que esta experiencia no es superficial; mejor, lo es en un sentido spinoziano. No invierte, sino que convierte en verdadera la imaginación del comunismo. La innovación sponiziana, en efecto, es una filosofía del comunismo, la ontología spinoziana no es más que una genealogía del comunismo"18.

La multitud, en la lectura de Negri -a la que después se suma Hardt-, es un conjunto inmanente de singularidades capaz de librarse de los mecanismos de opresión -fundamentalmente el que exige su inclusión en un sistema de representación- y reivindicar su poder, ligado, a partir de la célebre sentencia de Spinoza ("no se sabe lo que puede un cuerpo"), a la dimensión corporal: “el dispositivo de producción de subjetividad, que encuentra en la multitud su figura común, se presenta como práctica colectiva, como actividad siempre renovada de constitución del ser. El nombre de «multitud» es a la vez sujeto y producto de la práctica colectiva"19. Como podía esperarse, al dirigir el foco de atención hacia el cuerpo, la "multitud" de Negri enlaza con las reflexiones en torno al biopoder de Foucault, de lo que resulta una ontología para la que los 
entes son esos cuerpos singulares inmersos en procesos de subjetivación que se transforman en estrategias de resistencia frente al poder. Frente a la fijación de identidades, la indeterminación de la multitud; frente al ser como sustancia o hypokeimenon, la producción táctica de subjetividades inestables, difusas. Así es como "la resolución del problema de lo común de las singularidades, o incluso de lo común de las diferencias en cuanto diferencias, no puede pasar más que a través de un pensamiento no sólo positivo, sino afirmativo, es decir, ontológicamente potente" ${ }^{20}$. $\mathrm{Al}$ incidir en el carácter afirmativo de estos procesos de subjetivación, Judith Revel pretende alejarse de esa otra construcción de lo común "privativa y sustractiva" basada en "la ausencia de comunidad"21. De esta manera, las dos "ontologías de lo común" que venimos comentando parecen oponerse a la hora de examinar sus aplicaciones prácticas. Las diferencias no hacen sino aumentar cuando nos fijamos en las dos estéticas y en los dos tipos de arte a que han dado lugar.

\section{Lo común en la estética $y$ en el arte actuales}

No deja de ser significativo que todos los autores antes mencionados en algún momento se hayan ocupado de las implicaciones que las derivas ontológicas de sus filosofías pueden acarrear en dominios como el estético. Por otra parte, en el arte de las últimas décadas puede observarse un acreciente interés por estos pensadores cuyos trabajos dan pie a nuevas formas de pensar "lo común”. Desde el instante en que una de las funciones que asume una de las derivas más pujantes -y, todo hay que decirlo, exitosas- del arte actual es la de propiciar formas alternativas de comunidad en las que las identidades dejan de ser fijas y permanentes para ser inestables y temporales, el diálogo con las dos líneas filosóficas esbozadas en el epígrafe anterior resultaba inevitable. Gracias a este entrecruzamiento, los "filósofos de lo común" encontraron un terreno óptimo para visualizar sus teorías. Mientras, desde el otro lado, artistas y, sobre todo, críticos y teóricos se nutrieron de nociones tan complejas como "ser singular plural", "multitud" o "rizoma"22 para dotar a sus proyectos, exposiciones y manifiestos de hondura conceptual. Fruto de esta conexión son tres tendencias estéticas dependientes de premisas ontológicas y que poco a poco han ido adquiriendo protagonismo. En lo que sigue las examinaremos por separado:

1) el arte de la multitud: "finalmente, la posmodernidad es esto: la singularidad que se impone sobre la universalidad, la corporeidad que emerge como multitud irreductible, detentadora (y productora) de su propia ley. Es esta corporeidad singular lo que el arte de la multitud exalta (es decir, la sensatez de los cuerpos que se han reapropiado de la herramienta, que han hecho de ésta -en la red y en el éxodo- su prótesis)"233. Ya se vio cómo la ontología de la multitud tomaba de Spinoza una revalorización de lo corporal que ponía de relieve su carácter de potencia revolucionaria. No es de extrañar entonces que Negri haga del arte un medio al servicio de la liberación de los cuerpos oprimidos por el sistema de producción capitalista. El arte no es un reducto de ensoñaciones para evadirse de la realidad; tampoco se asemeja a un consuelo de fines terapéuticos. Es lo que devuelve al cuerpo su carácter ontológico y po- 
lítico. Ontológico, porque "si es cierto que el arte es un acto superior de la imaginación, en la medida en que accede directamente al ser, también es cierto que lo es de manera concentrada y fuerte, singular, una idea platónica que se construye y se muestra a través del desplegarse de la materia, un ejemplar"24. Político, por cuanto "su mecanismo productivo es democrático, en el sentido de que produce lenguaje, palabras, colores, sonidos que se arriman en comunidades, en nuevas comunidades" ${ }^{25}$.

Luego las obras del "arte de la multitud" combinan un carácter de singularidad, en cuanto despliegue material de una idea, con el propiamente múltiple, por las "nuevas comunidades" que originan. Esto último pone de manifiesto que estas creaciones son, ante todo, una actividad poética, o, mejor dicho, poïetica. El arte debe desencadenar una práctica revolucionaria consistente en la liberación de los cuerpos, acción que entraña la auto-constitución de un nuevo tipo de subjetividad -la multitud- gracias a ese "cuidado de sí", por decirlo en términos foucaultianos. De ahí que el arte que encontramos en esta tendencia, que Negri se resiste a denominar "estética", sea "una poética que atraviesa la «okupación» y navega en red, pinta a lo Basquiat en los transportes públicos y escribe poesía a lo Seattle... y propone en lo social, en la metrópoli, lucha de clases y liberación. Una lucha de apropiación de herramientas cada vez más potentes, de expresión de deseos cada vez más ricos y lenguajes cada vez más eficaces, de goce de una comunicación cada vez más abstracta y de una poética cada vez más singular"26.

Multitud singular. El arte de resistir fue el título que se dio a una exposición celebrada en 2009 en el Museo Reina Sofía de Madrid.
En el catálogo de la muestra, la comisaria Berta Sichel explicaba que "el título del proyecto está tomado de los textos del filósofo italiano Antonio Negri y las obras seleccionadas engloban relatos y documentos relacionados con la práctica contemporánea de la militancia política y la lucha contra el poder, ya sea colectiva o individual'"27. Sin embargo, pese a las palabras de Sichel, el resultado se alejó del propósito que las animaba. La poética que describía Negri difícilmente podía tener cabida en un museo, salvo que las prácticas que contemplaba fuesen presentadas en forma de documentos, de testimonios. La vida, la lucha por liberar los cuerpos, se libraba fuera de la institución museística, en donde las imágenes que recogían esas insurrecciones que acontecen en todo el mundo, carecían del poder "poético" de los propios acontecimientos. Por otro lado, las obras presentadas en Multitud singular formaban parte de un "programa de cine que examinara las relaciones entre arte y política según la configuración de la sociedad actual" 28 . El privilegio que, de esta manera, se concedía a lo visual no parecía encajar con la ontología que alentaba el proyecto y sí, en cambio, con una concepción metafísica en donde prima aquel sentido ${ }^{29}$. Tampoco se entiende cómo la mera percepción de testimonios audiovisuales de protestas políticas puede servir a esa otra empresa que es la creación del cuerpo como multitud, o esa otra de configuración de "las instituciones de lo común"30.

Aunque un solo ejemplo sea insuficiente para señalar una tendencia, lo cierto es que lo sucedido con esta exposición resulta sintomático de lo que sucede con la "ontología de la multitud" y el "arte de la multitud”. Las obras que describía Negri esta- 
ban a caballo entre el activismo y las reivindicaciones sociales en las grandes urbes, fuera, en cualquier caso, de una institución, el museo, que es, no se olvide, un espacio de poder, preso como cualquier otro de dicotomías como privado/público, individual/colectivo que, a priori, la "ontología de la multitud" recusa.

2) el arte de la comunidad: según Jean-Luc Nancy, "la cuestión «ontológica» de la unidad de la pluralidad de las artes no se ha planteado"31. El arte y la estética no pueden permanecer ajenos al hecho de que la lógica de la representación entró en crisis hace mucho tiempo y que, consiguientemente, defender que existe una idea del Arte, un último criterio con el que decidir qué encaja y qué no en esa categoría, es una falacia o un empeño nostálgico, el mismo que tiñe, por ejemplo, los escritos de Heidegger sobre arte, con sus referencias al "templo griego" o a las botas de Van Gogh. Las creaciones artísticas encajan en el pensamiento del "ser singular plural" (Nancy) o del "múltiple sin-uno" (Badiou), por cuanto no son subsumibles en una totalidad -el Arte, la Belleza...- de la que serían representaciones. En eso se asemeja a la imagen, la cual:

No es la imitación de una cosa más que en el sentido en que la imitación es la emulación de la cosa: rivaliza con la cosa, y la rivalidad no implica tanto la reproducción como la competición, y, para lo que nos ocupa, la competición con vistas a la presencia. La imagen le disputa a la cosa su presencia. En lugar de que la cosa se contente con ser, la imagen muestra que la cosa es y cómo es. La imagen es lo que saca a la cosa de su simple presencia para meterla en pre-sencia, en praes-entia, en ser-por-delante-de-sí, vuelto hacia el afuera. ${ }^{32}$

Como puede apreciarse, las imágenes poseen un estatuto ontológico similar al del $D a$ sein heideggeriano. Ellas son esos "seres singulares plurales" de los que habla Nancy. Lo sugerente de esta formulación, en especial cuando con ella se piensa qué son las imágenes, explica el interés que ha suscitado entre teóricos y artistas. En 2009 el Museo Guggenheim de Nueva York presentó una exposición titulada, precisamente, como el libro de Nancy: Ser singular plural. Curiosamente, el punto de partida no distaba mucho del de Multitud singular por el privilegio que se otorgaba a las imágenes:

En los trabajos presentados en la auto-reflexividad de los usos más tempranos del filme y el vídeo en la galería han sido reemplazados por un interés en investigar la imagen como una relación de mediación -una relación entre el yo y el otro, el artista y el mundo. [...] Las imágenes en movimiento de estos artistas representan una relación entre sujeto filmado y objeto filmado; son aserciones de coexistencia. Los artistas profundizan de diversas maneras en esta comprensión de la imagen en movimiento como una forma de "ser-con" y la usan para desmontar dicotomías entre yo y el otro, público y privado, arte y evidencia, y realidad y representación. ${ }^{33}$

La muestra presentaba un buen número de trabajos actuales de cineastas y videoartistas de la India con la doble finalidad de dar a conocer el arte de aquel país y de profundizar en la viabilidad de llevar los presupuestos ontológicos del "ser-con" al dominio de las creaciones artísticas. La iniciativa, si bien carecía del propósito eminentemente político de Multitud singular, hacía patente 
cómo las lecturas que desde el arte se han hecho de las “ontologías de lo común”, no sólo podían inspirar obras con un pretendido alcance crítico, sino que también podían contribuir a indagar en el modo de ser del arte. Es decir, a responder ya no a la pregunta ¿qué es arte?, sino a la de ¿cómo es el arte? Sin embargo, otros proyectos artísticos inspirados en la ontología de Nancy han preferido, en la línea de Multitud singular, continuar explorando las posibilidades que tiene el arte de propiciar formas de ser-con alternativas. Ahora bien, como antes se señaló, la única comunidad que encaja en esa premisa es la ya comentada del "nada en común", o sea, "la comunidad de los que no tienen comunidad" de Bataille. También se comentó cómo desde la "ontología de la multitud" se ha despreciado este pensamiento por su inoperancia política. Y, así como Nancy acaba preconizando la sustitución del término "comunidad" por el más ontológico del "ser-con", en autores como Negri, Revel o Virno es patente la insistencia por mantenerlo y por hacer del arte un vehículo para construir comunidades.

En los últimos años no han sido pocos los artistas y teóricos que han querido hacer suya la "communauté désoeuvrée" de Nancy y que se han topado con la dificultad que supone dotarla de eficacia política. Para empezar, el propio filósofo niega que el arte deba estar sometido a esquemas y programas de esa índole: "el arte no es un medio para cualquier cosa, es el nombre del conjunto de gestos por los que el hombre forma, se forma a sí mismo y da forma al mundo en el que vive. [...] El arte es una de las cosas más profundamente comunitarias, puesto que, lo digo con rotundidad, no es ni social ni político. Frecuentemente se oye lo contrario. Por mi parte, admito que el arte puede tener un rol político, pero su objeto no es directamente hacer política" ${ }^{34}$. Y, sin embargo, varias propuestas han intentado acometer esta traducción. En la 53 ${ }^{\mathrm{a}}$ Bienal de Venecia, de 2009, Valentín Roma presentó para el pabellón de Cataluña del que era comisario, el proyecto La comunitat inconfessable. Unas cuantas preguntas guiaban su empeño: “¿puede lo comunitario devenir un proyecto estético sin perder su esencia?, ¿la noción de autoría individual ha sido realmente sustituida? [...] ¿hay un arte de lo inconfesable?"35. Sobre la mesa quedaban unas cuantas cuestiones reunidas de manera un tanto confusa y que hubieran exigido, como propedéutica, una aclaración previa respecto al empleo que se le daba a "lo común". Sin ella, no quedaba claro si la comunidad a la que aludía el título -tomado del libro homónimo de Blanchot- era un modo de ser, una forma colectiva de creación artística o un resultado, una percepción estética a cargo del receptor. En su texto de presentación, Roma no deshacia la confusión, si bien enfatizaba que los trabajos reunidos para la ocasión coincidían en "adoptar la configuración de la comunidad no sólo como interfaz sino como ontología"36. En ellos, lo comunitario puede funcionar como sinónimo de "colectivo", en el caso del proyecto Sitesize, en el que lo común es la autoría; en Technologies To The People, ese "pueblo" aludido, informe y cargado de potencial crítico, está próximo a la "multitud" de Negri/Hardt. Por fin, la tercera de las propuestas, Archivo F.X, perseguía fomentar la creación de redes de comunicación alternativas a los cauces dominantes, en este caso a través de correspondencia.

La comunitat inconfessable constata cómo los proyectos que parten de las refle- 
xiones que desde la filosofía se ha hecho respecto a "lo común", se ven obligados a prescindir de aquel marco ontológico cuando se fijan objetivos claramente políticos, como es el de construir formas disensuales de comunidad opuestas a los distintos poderes y que en modo alguno encajan con la premisa del "nada en común". Resultado de ello es que la tendencia conocida como community art, en la que encaja el proyecto de Roma y que "propugna la creación y el mantenimiento de una práctica de comunidad entre sponsor, artista, obra y público"37, entraña una concepción de lo común totalmente alejada de las ontologías que venimos comentando, pese a que manifieste tener a Negri entre sus referentes.

3) el arte del disenso: "la ruptura estética ha instalado una singular forma de eficacia: [...] la eficacia de un disenso. Lo que entiendo por disenso no es el conflicto entre ideas o sentimientos. Es el conflicto entre varios regímenes de sensorialidad. Ahí es por donde el arte, en el régimen de la separación estética, llega a tocar a la política. Pues es disenso está en el corazón de la política"38. El "arte disensual" lo integran aquellos trabajos artísticos que viene analizando en los últimos tiempos el filósofo francés Jacques Rancière, y que proponen una idea de lo común alejada de aquélla presente en las ontologías de lo común. En sus escritos, este autor critica sin ambages una tendencia que ha tenido bastante éxito en los últimos años en el mundo del arte, la de "lo relacional", término acuñado por el crítico Nicolas Bourriaud a finales de los años $90^{39}$ que engloba a aquellas prácticas que pretenden fomentar la recuperación y reconstrucción de los lazos sociales a través del arte. El análisis de Bourriaud, que no oculta su deuda con el diag- nóstico de la realidad hecho por Guy Debord en La sociedad del espectáculo, aboga por un arte que constituya modos de existencia o modelos de acción en el interior de lo real existente, como hacen en sus trabajos Rikrit Tiravanija, Philippe Parreno, Carsten Höller, Liam Gillick o Christine Hill. Así, las nuevas formas relacionales se presentan como formas micropolíticas de resistencia alternativas al discurso del poder.

Pese a estas intenciones, el "arte relacional”, según Rancière, no llega a propiciar verdaderos vínculos alternativos que cuestionen lo que él denomina "el reparto de lo sensible", esto es, la configuración del espacio común en el que reina la desigualdad de todo tipo (económica, política, social...) al asignar de antemano los lugares y roles que los sujetos ocupan en el orden sensible, en la realidad. Alterar tales identidades es, en consecuencia, una operación estética: una reconfiguración del espacio de percepción y de acción para que excluidos -principalmente minorías como los inmigrantes "sin papeles"puedan hacer que sus voces sean escuchadas. Es precisamente aquí, en ese acto de enunciación que profieren los marginados, en donde Rancière recupera ese otro común no ontológico ${ }^{40}$ : el sensus communis kantiano

La aparente paradoja de esta lucha colectiva por un lugar único es sencilla de resolver: la posibilidad de estar solo(a) aparece como la forma de relación social, la dimensión de la vida social que precisamente se ha hecho imposible por las condiciones de vida en las banlieus. Este lugar vacío dibuja por el contrario una comunidad de personas que tienen la posibilidad de estar solas. Significa la igual capacidad de los miembros de una colectividad por ser un Yo cuyo juicio puede ser atribuido a cualquier otro y crear así, sobre el mo- 
delo de la universalidad estética kantiana, una nueva forma de Nosotros, una comunidad estética o disensual. ${ }^{41}$

El disenso es la clave para alcanzar esa “Otra relacionalidad" a la que se refería el título del seminario que se desarrolló en el MACBA entre 2005 y 2006. El espacio, un museo, ponía de manifiesto el papel que el arte juega en la construcción de esas comunidades disensuales en las que lo común apela a una capacidad de sensibilidad universalmente compartida. Con todo, casi resulta inevitable identificar ese Nosotros anónimo con la multitud de Negri. En ambos casos, el acontecimiento revolucionario pasa por la configuración de subjetividades de carácter no permanente. Asimismo, la misma universalidad del sensus communis kantiano podría ser leída, como hace Esposito, como el instante en el que el Yo pierde su carácter de sujeto $^{42}$, abriendo las puertas a esos procesos intermitentes y ocasionales en los que las subjetividades van ocupando tácticamente el espacio vacío dejado por el sujeto cartesiano. En definitiva, pese a afirmar sus reticencias con las ontologías de lo común, la misión que Rancière otorga al arte como propiciador de disensos invita a pensar, de nuevo, problemas tales como la crisis de la subjetividad de la que aquéllas son también respuesta.

\section{Conclusión}

El interés con el que la estética y el arte actuales han acogido la idea de "lo común" procedente de pensamientos con un marcado sesgo ontológico, como es el caso de las obras de Jean-Luc Nancy, Alain Badiou o Toni Negri, ha dado lugar a unas propuestas artísticas que aspiran a alcanzar resultados políti- cos. La visualización de las desigualdades socio-económicas, la revalorización de lo corporal o la creación de subjetividades reacias son algunas de las metas que se fijan muchos de los proyectos basados en las "ontologías de lo común”. Sin embargo, los resultados alcanzados distan mucho de ser los esperados. En algunos casos, las obras presentadas no son sino meros testimonios visuales de prácticas y acciones políticas no necesariamente artísticas. Su potencia crítica es, por ello, reducida. Otras veces, el uso que hacen de las nociones de "comunidad" o "multitud" deja de lado sus presupuestos ontológicos, con lo que obvian la complejidad de una cuestión crucial como es la de la dialéctica singularidad-multiplicidad o la del "estar-juntos sin ensamblaje".

La demanda que se le hace al arte para que asuma un carácter comprometido y desarrolle una crítica del orden hegemónico, parece pasar entonces por su papel como mediador para la creación de nuevas formas de comunidad que encajen con movimientos políticos de resistencia. Las propuestas que han asumido ese reto oscilan entre la reflexión acerca del estatuto ontológico de las imágenes desde el pensamiento del ser-con (Being Singular Plural) y el impulso a proyectos artísticos de carácter político (Multitud Singular, La Comunitat Inconfessable, Otra relacionalidad...) basados en una idea de lo común que no se adaptan a las premisas del "singular plural" de Nancy, del "múltiple sin-uno" de Badiou o, incluso, del "arte de la multitud" de Negri. En cambio, sí remiten a una idea de comunidad, la de la tercera Crítica kantiana. El sensus communis ofrece desde una perspectiva bien distinta, al margen de la ontología, una universalidad no reñida con la subjetividad del receptor, lo que ofrece una alternati- 
va a pensar lo común desde unas coordenadas más familiares a las estéticas analizadas, que pese al interés que muestran por lo que hemos denominado "las ontologías de lo común”, demuestran no estar capacitadas para dar una solución desde su dominio a las dificultades que aquéllas presentan.

\section{REFERENCIAS BIBLIOGRÁFICAS}

Agamben, G., La comunidad que viene, trad. de José Luis Villacañas, Claudio La Rocca y Ester Quirós, Pre-textos, Valencia, 1996.

Badiou, A., L'être et l'événement, Seuil, Paris, 1988.

Badiou, A., Court traité d'ontologie transitoire, Seuil, Paris, 1998.

Badiou, A., "Un, multiple, multiplicité(s)", en Multitudes $\mathrm{n}^{\circ} 1$ (2000).

Blanchot, M., La communauté inavouable, Éditions de Minuit, Paris, 1983.

Blanchot, M., La comunidad inconfesable, trad. de Isidro Herrena, Arena, Madrid, 2002.

Bolsom, E., "Cinema, Scattered", en Being Singular Plural, Guggenheim Foundation, New York, 2010, pp. 115-120.

Bourriaud, N., Esthétique relationnelle, Les presses du réel, Dijon, 1998.

De Bruyne, P. y Gielen, P., "Introduction. Between the Individual and the Common", en De Bruyne, P. y Gielen, P. (eds.), Community Art. The Politics of Trespassing, Valiz, Amsterdam, 2009, pp. 1-11.

Deleuze, G., La isla desierta, trad. de José Luis Pardo, Pre-textos, Valencia, 2005.

Derrida, J., La escritura y la diferencia, trad. de Patricio Peñalver, Anthropos, Barcelona, 1989.
Derrida, J. Políticas de la amistad, trad. de Patricio Peñalver y Paco Vidarte, Trotta, Madrid, 1998.

Esposito, R., Communitas, trad. de Carlo Rodolfo Molinari, Amorrortu, Buenos Aires, p. 128

Fraser, N., Unruly practices: power, discourse and gender in contemporary social theory, Polity Press, Cambridge, 1989.

Heidegger, M., Ser y tiempo, trad. de Jorge Eduardo Rivera, Trotta, Madrid, 2009.

Lacoue-Labarthe, P., "Typographie”, en $\mathrm{Mi}$ mesis des articulations, Aubier / Flamarion, Paris, 1975, pp. 167-270.

Lacoue-Labarthe, P. y Nancy, J.-L., Le mythe nazi, Ed. de l'Aube, La Tour d'Aigues, 1991.

Lyotard, J.-F., "Sensus communis: le sujet à l'état naissant", en Cahiers Confrontation $\mathrm{n}^{\circ} 20$ : Après le sujet qui vient (1989), pp. 161-179.

Nancy, J.-L., La communauté désoeuvrée, Christian Bourgois, Paris, 1986.

Nancy, J.-L., Etre singulier pluriel, Galilée, Paris, 1996.

Nancy, J.-L., Les Muses, Galilée, Paris, 2001.

Nancy, J.-L., Au fond des images, Galilée, Paris, 2003.

Nancy, J.-L., "Jacques Rancière et la métaphysique", en Cornu, L. y Vermeren, P. (eds.), La philosophie déplacée, Paris, Horlieu, 2006, pp. 155-167.

Nancy, J.-L., "Quelle(s) communauté(s) après l'effondrement du communisme et à l'heure du réveil des communautarismes?", en Truong, N. (ed.), Le Théâtre des idées, Flammarion, 2008, pp. 315-316.

Negri, T., "«Retour à Spinoza» et le retour du communisme", en Spinoza subversifVariations (in)actuelles, Kimé, Paris, 1994, pp. 131-139. 
Negri, T., Arte y multitudo: ocho cartas, trad. de Raúl Sánchez, Trotta, Madrid, 2000.

Negri, T., "Pour une définition ontologique de la multitude", en Multitudes n ${ }^{\circ} 9$ (2002).

Negri, T. La fábrica de porcelana, trad. de Susana Lauro, Paidós, Barcelona, 2008.

Rancière, J., Le Spectateur émancipé, La fabrique, Paris, 2008.

Revel, J., "Sobre las resistencias, las subjetividades y lo común", en Multitud singular. El arte de resistir, MNCARS, 2009.
Revel, J., "Construire le commun", en Rue Descartes $n^{\circ} 67$ (2010), CIPH, Paris.

Rodríguez, C., "Jean-Luc Nancy y Maurice Blanchot. El reparto de lo inconfesable", en Revista Escritura e Imagen $\mathrm{n}^{\circ} 8$ (2012), Universidad Complutense de Madrid, pp. 259-276.

Roma, V., "La Comunidad Inconfesable", en La Comunidad Inconfesable, Actar, Barcelona, 2009, pp. 9-21.

Sichel, B., "Presentación", en Multitud singular. El arte de resistir, MNCARS, 2009.

\section{NOTAS}

* El presente trabajo es resultado de una investigación emprendida gracias a un contrato de Personal Investigador de la Comunidad de Madrid, en el período 2008-2012.

${ }^{1}$ Cfr. Blanchot, M., La communauté inavouable, Éditions de Minuit, Paris, 1983; Nancy, J.-L., La communauté désoeuvrée, Christian Bourgois, Paris, 1986.

${ }^{2}$ Valgan como ilustración tres críticas procedentes de tradiciones completamente alejadas. En "The French Derrideans", Nancy Fraser subraya la ineficacia práctica de la propuesta de Nancy y de Lacoue-Labarthe, articulada desde su idea de lo "común" y de la "retirada de lo político" (Cfr. Fraser, N., "The French Derrideans", en Fraser, N., Unruly practices: power, discourse and gender in contemporary social theory, Polity Press, Cambridge, 1989). A una conclusión parecida llega Toni Negri en La fábrica de porcelana, que denuncia los presupuestos "místicos" -léase políticamente inútiles- del pensamiento de Nancy (en Negri, T. La fábrica de porcelana, trad. de Susana Lauro, Paidós, Barcelona, 2008, p. 207). Por último, un autor próximo tanto a Blanchot como a Nancy, Jacques Derrida, no dejó de manifestar sus reticencias respecto al empleo que éstos hacían de la fórmula "comunidad sin comunidad" (Cfr. Derrida, J. Politicas de la amistad, trad. de Patricio Peñalver y Paco Vidarte, Trotta, Madrid, 1998, pp. 55-56).
${ }^{3}$ Un minucioso análisis y discusión de las posiciones de ambos filósofos puede encontrarse en el texto de Cristina Rodríguez "Jean-Luc Nancy y Maurice Blanchot. El reparto de lo inconfesable", en Revista Escritura e Imagen n ${ }^{\circ} 8$ (2012), Universidad Complutense de Madrid.

${ }^{4}$ Cfr. Revel, J., "Construire le commun", en Rue Descartes n 67 (2010), CIPH, Paris.

${ }^{5}$ Heidegger, M., Ser y tiempo, Trotta, Madrid, 2009, p. 139.

${ }^{6}$ Ibid.

${ }^{7}$ Ibid., p. 398.

${ }^{8}$ La referencia a los trabajos de Philippe Lacoue-Labarthe sobre el uso que de la "figura" hace lo que él denomina la "onto-tipología", es obligada. Cfr. Lacoue-Labarthe, P., "Typographie", en Mimesis des articulations, Aubier / Flamarion, Paris, 1975, pp. 167-270.

${ }^{9}$ Así se titula un epígrafe de la fundamental obra de Nancy Être singulier pluriel (Galilée, Paris, 1996), uno de los diálogos con Heidegger más complejos y ricos de las últimas décadas.

${ }^{10}$ Nancy, J.-L., "La comunidad afrontada", en Blanchot, M., La comunidad inconfesable, trad. de Isidro Herrena, Arena, Madrid, 2002, p. 109.

${ }^{11}$ Cfr. Lacoue-Labarthe, P. y Nancy, J.-L., Le mythe nazi, Ed. de l'Aube, La Tour d'Aigues, 1991.

${ }^{12}$ Nancy, J.-L., Etre... op. cit., p. 46. [Salvo que se indique lo contrario, la traducción de las citas extraídas de los textos originales es nuestra] 
${ }^{13}$ Agamben, G., La comunidad que viene, Pretextos, Valencia, 1996, pp. 82-83.

${ }^{14}$ Badiou, A., Court traité d'ontologie transitoire, Seuil, Paris, 1998, p. 28.

${ }^{15} \mathrm{Cfr}$. Badiou, A., L'être et l'événement, Seuil, Paris, 1988, p. 143.

${ }^{16}$ Ibid., p. 37.

${ }^{17}$ Badiou, A., "Un, multiple, multiplicité(s)", en Multitudes n ${ }^{\circ} 1$ (2000). Disponible en http://multitudes.samizdat.net/Un-multiplemultiplicite-s (última consulta, 20-07-2012)

${ }^{18}$ Negri, T., "«Retour à Spinoza» et le retour du communisme", en Spinoza subversif- Variations (in)actuelles, Kimé, Paris, 1994, pp. 131-139.

${ }^{19}$ Negri, T., "Pour une définition ontologique de la multitude", en Multitudes no 9 (2002). Disponible en http://multitudes.samizdat.net/Pourune-definition-ontologique-de (última consulta, 20-07-2012).

${ }^{20}$ Revel, J., "Construire le commun: une ontologie", op. cit.

${ }^{21}$ Ibid.

${ }^{22}$ Aunque en el anterior apartado no se ha mencionado el nombre de Deleuze, es obvio que su trabajo presenta rasgos afines con los de estas "ontologías de lo común". En efecto, haciéndose cargo de la crítica nietzscheana del sujeto, Deleuze aboga por unas "individuaciones impersonales, o incluso singularidades pre-individuales", fruto de "las multiplicidades, las masas y las manadas, los pueblos y las tribus, los dispositivos colectivos que nos atraviesan, que están dentro de nosotros y que no conocemos porque forman parte de nuestro propio inconsciente". El suyo es un pensamiento que ofrece otra posibilidad de pensar lo singular junto a lo múltiple y que se encarna en la fascinante imagen del rizoma. Cfr. Deleuze, G., La isla desierta, Pre-textos, Valencia, 2005, pp. 180 y 349.

${ }^{23}$ Negri, T., Arte y multitudo: ocho cartas, trad. de Raúl Sánchez, Trotta, Madrid, 2000, p. 46.

${ }^{24}$ Ibid., p. 22.

${ }^{25}$ Ibid., p. 32.

${ }^{26}$ Ibid., p. 47.

${ }^{27}$ Sichel, B., "Presentación", en Multitud singular. El arte de resistir, MNCARS, 2009, p. 4.

${ }^{28}$ Ibid., p. 3.
${ }^{29}$ Cfr. Derrida, J., "Violencia y metafísica", en La escritura y la diferencia, Anthropos, Barcelona, 1989.

${ }^{30}$ Revel, J., "Sobre las resistencias, las subjetividades y lo común", en Multitud singular, op. cit., p. 64.

${ }^{31}$ Nancy, J.-L., Les Muses, Galilée, Paris, 2001, p. 13

${ }^{32}$ Nancy, J.-L., Au fond des images, Galilée, Paris, 2003, p. 46.

${ }^{33}$ Bolsom, E., "Cinema, Scattered", en Being Singular Plural, Guggenheim Foundation, New York, 2010, p. 116.

${ }^{34}$ Nancy, J.-L., "Quelle(s) communauté(s) après l'effondrement du communisme et à l'heure du réveil des communautarismes?", en Truong, N. (ed.), Le Théâtre des idées, Flammarion, 2008, pp. 315-316.

35 Roma, V., "La Comunidad Inconfesable", en La Comunidad Inconfesable, Actar, Barcelona, 2009, p. 17.

${ }^{36}$ Ibid., p. 18.

${ }^{37}$ De Bruyne, P. y Gielen, P., "Introduction. Between the Individual and the Common", en De Bruyne, P. y Gielen, P. (eds.), Community Art. The Politics of Trespassing, Valiz, Amsterdam, 2009, p. 4.

${ }^{38}$ Rancière, J., Le Spectateur émancipé, La fabrique, Paris, 2008, p. 66.

${ }^{39}$ Bourriaud, N., Esthétique relationnelle, Les presses du réel, Dijon, 1998.

${ }^{40}$ Respecto a las reticencias de Rancière hacia las posiciones ontológicas, en especial la de Nancy, cfr. Nancy, J.-L., "Jacques Rancière et la métaphysique”, en Cornu, L. y Vermeren, P., $L a$ philosophie déplacée, París, Horlieu, 2006, pp. 155-167

${ }^{41}$ Rancière, J., op. cit., p. 70.

${ }^{42}$ Esposito, R., Commnitas, Amorrortu, Buenos Aires, p. 128. Años antes, Lyotard había llegado a la misma conclusión al sostener que en el sensus communis estaba "el sujeto en estado naciente". Cfr. Lyotard, J.-F., "Sensus communis: le sujet à l'état naissant", en Cahiers Confrontation $\mathrm{n}^{\circ} 20$ : Après le sujet qui vient (1989). 